\title{
Intraneural ganglia: a clinical problem deserving a mechanistic explanation and model
}

\author{
Shreehari Elangovan, B.E., ${ }^{1}$ Gregory M. Odegard, Ph.D., ${ }^{1}$ Duane A. Morrow, M.S., ${ }^{2}$ \\ Huan Wang, M.D., Ph.D., ${ }^{3}$ Marie-Noëlle Hébert-Blouin, M.D., ${ }^{3}$ \\ ANd Robert J. SPINNER, M.D. ${ }^{3}$ \\ ${ }^{1}$ Department of Mechanical Engineering-Engineering Mechanics, Michigan Technological University, \\ Houghton, Michigan; and ${ }^{2}$ Orthopedic Biomechanics Laboratory and ${ }^{3}$ Department of Neurosurgery, \\ Mayo Clinic, Rochester, Minnesota
}

\begin{abstract}
Intraneural ganglion cysts have been considered a curiosity for 2 centuries. Based on a unifying articular (synovial) theory, recent evidence has provided a logical explanation for their formation and propagation. The fundamental principle is that of a joint origin and a capsular defect through which synovial fluid escapes following the articular branch, typically into the parent nerve. A stereotypical, reproducible appearance has been characterized that suggests a shared pathogenesis. In the present report the authors will provide a mechanistic explanation that can then be mathematically tested using a preliminary model created by finite element analysis. (DOI: 10.3171/FOC.2009.26.2.E11)
\end{abstract}

KeY Words • cyst • finite element analysis • intraneural ganglia

I NTRANEURAL ganglion cysts are mucinous lesions found within the epineurium of nerves. They occur most commonly in the peroneal nerve but have been described in many nerves in the vicinity of synovial joints. These intraneural ganglion cysts typically result in neurological deficit due to the displacement of nerve fascicles by the cyst contents. ${ }^{44,45,47}$

Intraneural ganglion cysts have been considered curiosities for 2 centuries. Different theories, without a scientific basis, have been proposed. 4,6-8,15,19,20,24,27 The articular (synovial) theory, ${ }^{42,45}$ based on robust clinical, imaging, and histological evidence, ${ }^{11,39-42,44,45,47,49,50}$ provides a logical, consistent explanation that clarifies and unifies the observations made by many over the years. Developed on the prototype of the peroneal nerve ganglion cysts, the theory can be extrapolated to intraneural ganglion cysts involving other nerves. The core principle for the formation of these cysts is a joint connection via an articular branch. This finding can be reliably demonstrated with imaging and at operation provided appropriate techniques and experience. ${ }^{44,45}$ The fact that these articular connections may be small, ${ }^{36,44}$ seemingly remote, $, 31,32,43,54$ and externally normal ${ }^{34}$ explains why they may not be readily recognized and why other theories have been proposed.

The recent characterization of predictable, stereotypical patterns of growth of intraneural ganglia ${ }^{42,45,46}$ as demonstrated by the peroneal nerve model (Fig. 1),

Abbreviation used in this paper: FEA = finite element analysis. suggests that they are the result of a shared mechanism. Thus, it appears that this clinical problem can be simulated and solved. The design of a model would help define the precise pathogenesis underlying the formation and propagation of intraneural ganglia, and this in turn could refine treatment modalities. In this report we will provide a mechanistic explanation that then can be mathematically tested with a preliminary model created by using FEA.

\section{Mechanistic Explanation}

The mechanistic explanation of intraneural ganglion cyst consists of the analysis of the mechanical interactions of the cyst fluid, the nerve tissue (for example, epineurium), and the tissue surrounding the nerve (for example, muscle, bone, soft tissue) in relation to the environment (for example, gravity). As the mechanical interactions are specific to each interface (1] joint-capsule, 2] capsulearticular branch, 3] articular branch-parent nerve, and 4] parent nerve-proximal major nerve interfaces), each will be described individually. For simplicity, the peroneal nerve, the most common site for an intraneural ganglion cyst, will be used as the prototype. However, this mechanistic explanation can be applied to intraneural ganglion cyst of any nerve.

\section{Joint-Joint Capsule Interface}

The formation of the intraneural ganglion cyst oc- 


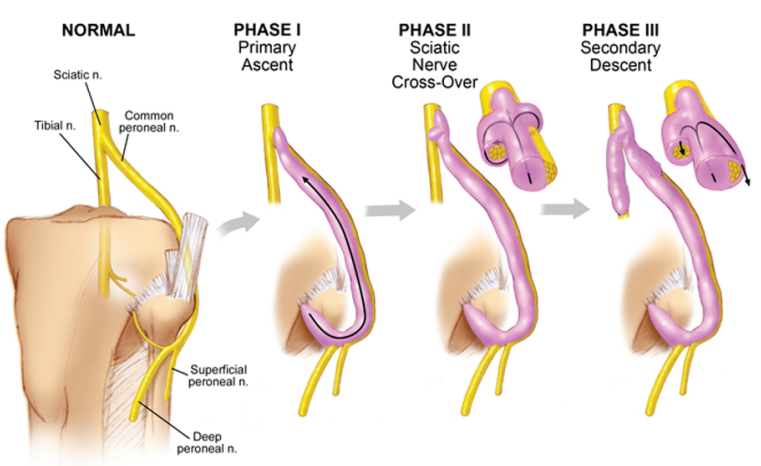

FIG. 1. A predictable phasic pattern for intraneural cyst formation and propagation in peroneal intraneural ganglia has been observed and described. Primary ascent (Phase I) allows cyst fluid derived from the anterior portion of the superior tibiofibular joint dissects along the articular branch into the common peroneal nerve. Cross-over (Phase II) occurs with expansion within the common epineurial sheath of the sciatic nerve. Secondary descent (Phase III) down the tibial and/or peroneal nerves can occur after cross-over. In this figure, the predominant primary ascending pathway is shown (primary descent, which is typically less prominent, may occur within the proximal portions of the deep and superficial peroneal nerve branches and is not depicted). $n=$ nerve. Modified with permission from Spinner RJ, et al: Dynamic phases of peroneal and tibial intraneural ganglia formation: a new dimension added to the unifying articular theory. J Neurosurg 107:296-307, 2007.

curs at the joint-joint capsule interface. Joint fluid is produced by the synovium of the joint and escapes through a capsular defect (rent). The capsular defect may be preex-

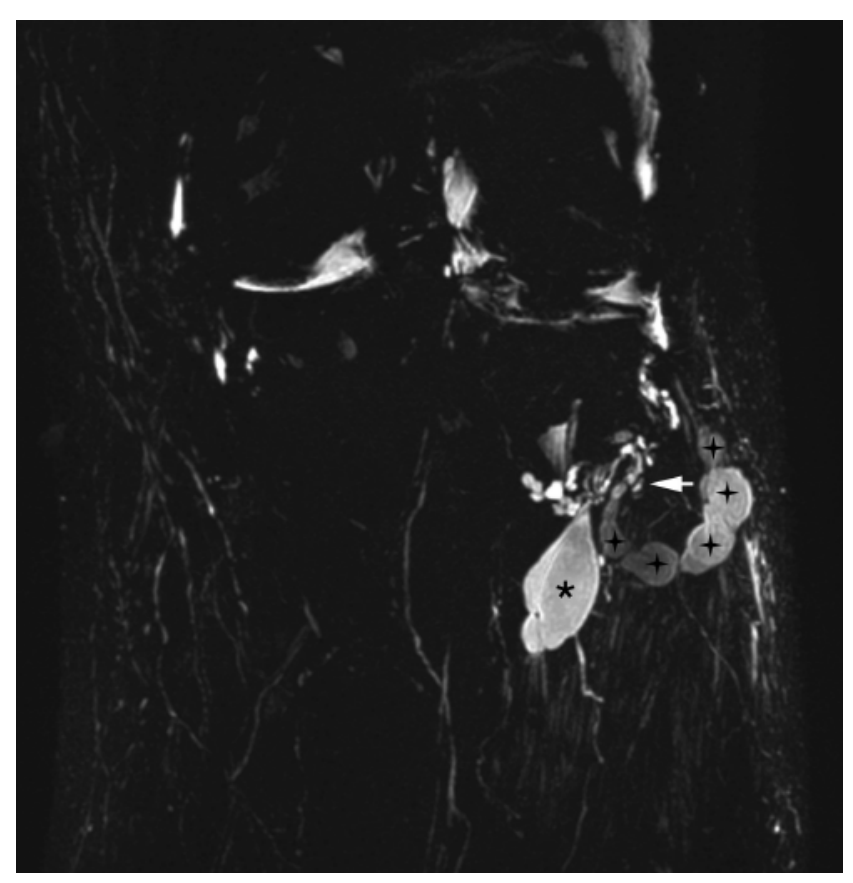

FIG. 2. Oblique coronal MIP (maximum intensity projection) image made from a VIPR (vastly undersampled isotropic projection reconstruction) data set shows a peroneal intraneural cyst arising from the superior tibiofibular joint (arrow) and extending via the articular branch into the parent common peroneal nerve (plus signs). Note the extraneural cyst (asterisk), which extends from the joint into the anterior compartment. isting and is likely the result of a traumatic, degenerative, or congenital process. ${ }^{11,44,45}$ In the peroneal intraneural ganglia model, evidence suggests that direct or indirect cumulative trauma ${ }^{13,14,20,44}$ to the superior tibiofibular joint itself or in relation to the neighboring (and often communicating) knee joint is important in the development of the cysts. ${ }^{45}$ Increased intraarticular pressure (that is, static or dynamic) is the other mechanism involved at the jointjoint capsule interface. Prior to the escape of the fluid through the defect, increased intraarticular pressure may lead to bulging of the joint capsule. This is possibly due to the relative ease to expand the capsular tissue initially. As the intraarticular pressure increases, the potential energy of the system increases. In accordance with the principle of minimum potential energy, it is then easier for the fluid to escape through the rent than to expand the capsule further. The synovial fluid "chooses" the path of least resistance. In the absence of a rent, increased pressure could result in rupture of the capsule.

\section{Joint Capsule-Articular Branch Interface}

In intraneural ganglion cysts the capsular rent is closely associated with an articular branch; in contrast, in extraneural ganglia the rent is distinct from the articular branch. At times, these 2 types of cysts can coexist (Fig. 2). In intraneural ganglia, the synovial fluid enters the articular branch. While a joint "connection" of the articular branch to a neighboring synovial joint can be well seen on imaging and at surgery, the direct "communication" between the joint and the cyst has been demonstrated on arthrography. ${ }^{10,18,23,26,31,32,40,41}$ Once the fluid has entered the nerve, the increased intraarticular pressures can result from: 1) continued production of synovial fluid within the joint and 2) the dynamic increase in intraarticular pressure associated with loading and joint mechanics. These increased forces would logically lead to an increase in the pressure within the newly initiated cyst. Resulting forces from the joint promoting cyst formation are greater than the resisting forces (Fig. 3). Resisting forces can be either intrinsic or extrinsic. Intrinsic resisting forces relate to the resistance to the elastic deformation of the nerve. Extrinsic resisting forces come from the surrounding tissue such as bone, muscle, or soft tissue (such as compartments). Gravity can also play a role in facilitating or resisting cyst propagation. The role of cyst resorption and/or the potential for rupture is unknown.

It seems intuitive that in clinically apparent, persistent cysts, the intraarticular pressure remains larger than the resisting forces, resulting in further cyst formation: expansion (in diameter) and extension (in length). Expansion and extension are further favored for two reasons: 1) maintenance of joint forces (that is, synovium continues to produce fluid, in fact probably at an increased rate due to the association of joint-related disease), and 2) the relative ease of further cyst growth (that is, increased volume of the cyst results in a reduction of the intrinsic resisting forces). This observation would be consistent with the path of least resistance, which is illustrated by the well-established principle of energy minimization. Less energy is required for cyst expansion and extension, in view of the relatively weak neural tissue (especially in 


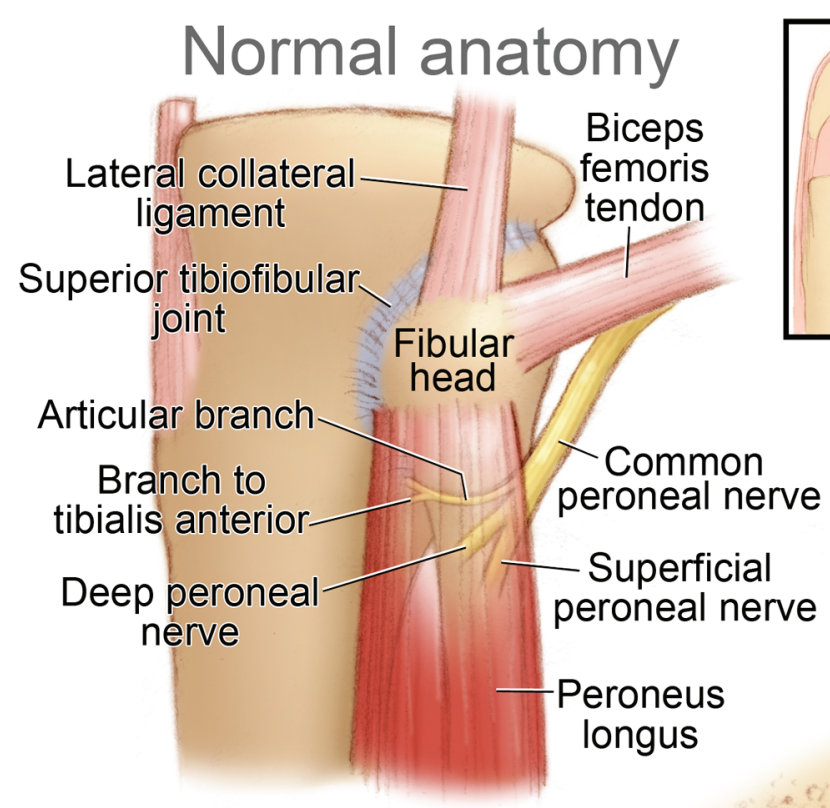

Axial loading

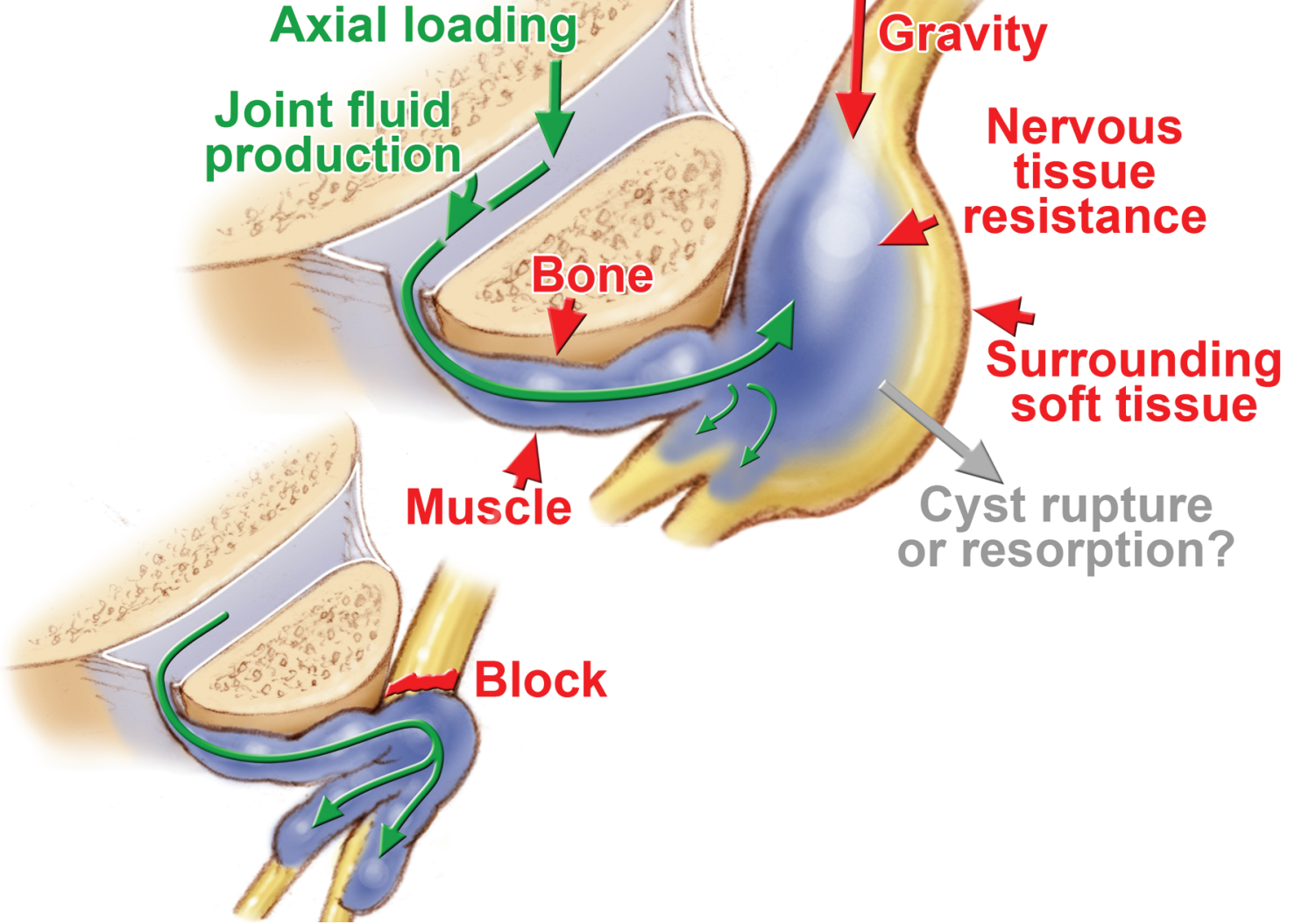

FIG. 3. The normal anatomy of the common peroneal nerve and its branches is shown in relation to the superior tibiofibular joint. A typical peroneal intraneural ganglion cyst (pathoanatomy) is illustrated. Its common features include: a cystic articular branch with balloon-like expansion at the level of the common peroneal nerve and preferential proximal ascent. These features suggest a common mechanism to explain their hallmark appearance. The different proposed forces playing a role in intraneural ganglia are shown. Increased intraarticular forces (joint fluid production and axial loading) facilitate the formation and propagation of the intraneural cyst (green labels). Resisting forces (nerve tissue, bone, muscle, soft tissue and gravity) are labeled in red. The unclear role of cyst resorption and/or rupture is shown in gray. Atypical patterns can be seen and explained by the presence of additional forces, such as a block (for example, caused by scar, surgery) that redirect the cyst into different pathways. Upper panel: Reproduced with permission from Spinner RJ, et al: Peroneal intraneural ganglia. Part I. Techniques for successful diagnosis and treatment. Neurosurg Focus 22(6):E16, 2007. Lower Panel: Printed with permission of Mayo Foundation, 2008. 


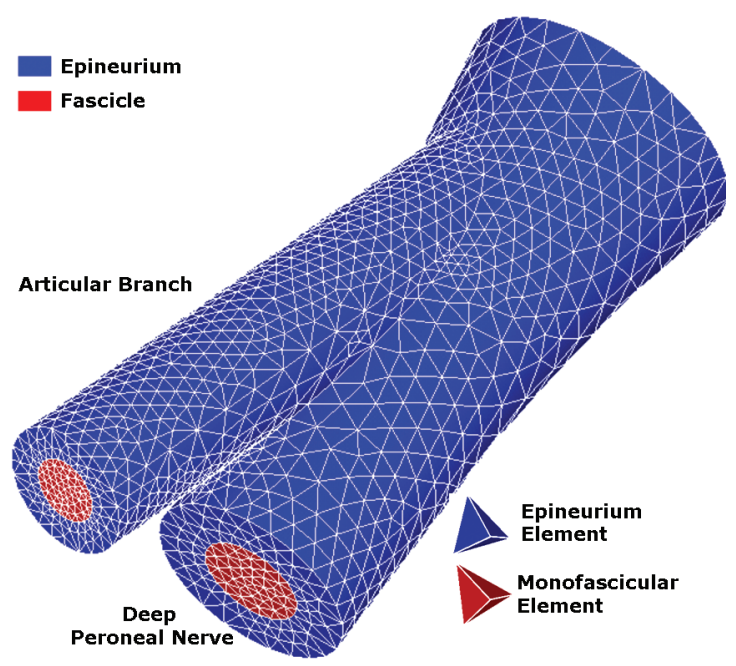

FIG. 4. An FEA model of the junction between the articular branch and the deep peroneal nerve. Two different nerve components are represented: the epineurial region (blue) and the fascicular region (red). Each region is assigned different material properties (that is, stiffness, strength, and so on). The triangular lines on the exterior imply building blocks called elements, which can be arranged to represent the mechanical behavior of the representative anatomical regions.

the epineurium), than for fluid reentry into the joint. The presence (or absence of) and type of valve is unknown.

\section{Articular Branch-Parent Nerve Interface}

At the articular branch-parent nerve interface, the same factors as those discussed above apply. With continued cyst growth, extension occurs within the confines of the epineurium into a parent nerve. At the articular branch-parent nerve junction, the cyst again follows the path of least resistance. It can either extend proximally and/or distally to varying levels. Contributing factors could include: 1) the degree of angulation of the articular branch to the parent nerve; 2) the relative location of the cyst within the articular branch and its specific position as it reaches the articular-parent nerve junction (favoring growth along rather than around strong and stiff fascicles); and 3) increased additional resistances from intrinsic or extrinsic factors such as scarring or ligation. Any combination of these factors could dictate directionality. As clinical observation suggests, cyst expansion tends to be eccentric, displacing nerve fascicles ("signet ring" sign) ${ }^{47}$ Assuming the absence of a morphological defect, the intraepineurial cleavage plane (specifically, within the outer epineurium) seems to be favored clinically. This could be explained by dissection according to the path of least resistance: 1) the outer epineurium appears to have less resistance than the combined inner epineurium and fascicles and 2) the continued forces promote cyst propagation within the same neural compartment. The crosssectional anatomy of the articular branch and parent nerve interface is not well known; the location at which a well-defined inner and outer epineurium exists has not been characterized.

The articular branch is a small nerve branch and the diameter of its cystic enlargement in intraneural ganglia is relatively small compared with that of the parent nerve. This gives rise to the characteristic imaging features of intraneural ganglion cysts: a tubular cyst constrained by the epineurium with a small neck ("tail" sign) and balloon-like cystic involvement of the parent nerve (Fig. 2). The size and shape of the cyst in different regions are dictated by the architecture and diameter of respective neural branches and extrinsic forces overlying the neural tissues. The multilobulated but elongated appearance often seen clinically can potentially be due to the dynamic nature of the intraarticular pressures and variable effects from other forces. In contrast, the extrinsic and intrinsic forces for the formation of extraneural ganglia differ; their appearance tends to be more globular when they occur in soft tissue.

\section{Parent Nerve-Proximal Major Nerve Interface}

When a cyst propagates proximally and joins with another nerve, the cyst can either expand or elongate
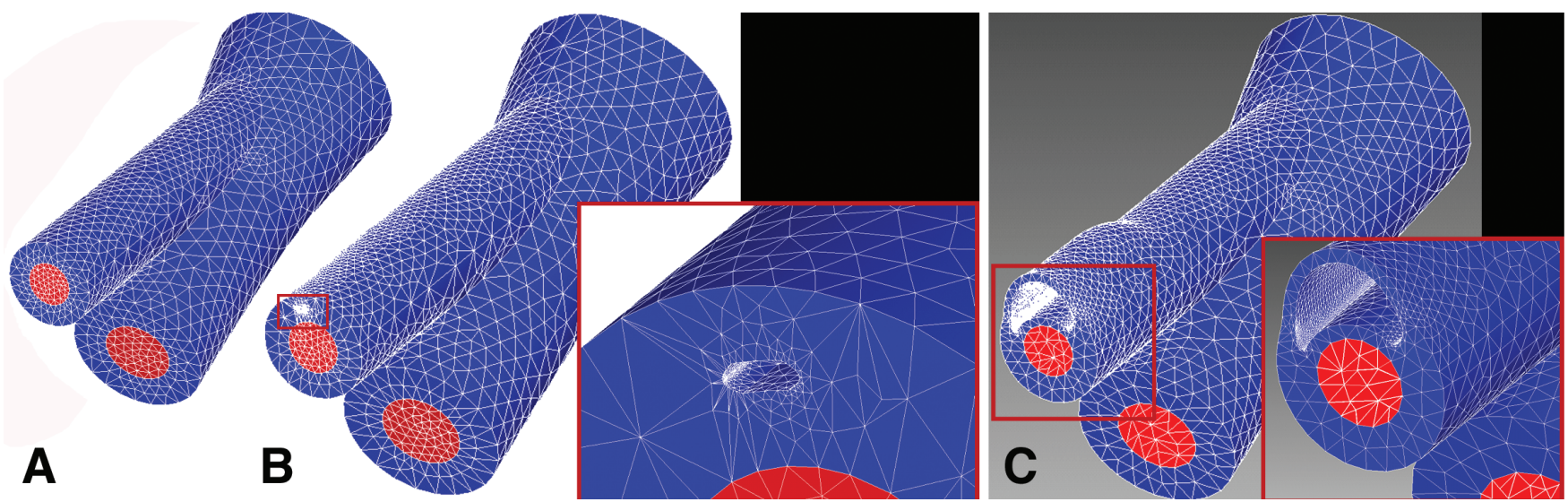

FIG. 5. Modeling of the development of an intraneural cyst. A: The FEA model without a cyst in the articular branch. B: The FEA model showing a small cleavage plane and the initiation of an intraneural cyst formation within the articular branch. A microscopic crack (inset) allows the influx of synovial fluid from the joint into the articular branch, initiating the process. C: At a more advanced stage (than in B), further influx of synovial fluid leads to growth and propagation of the intraneural cyst. This modeling appearance resembles the clinical appearance in intraneural ganglia. 


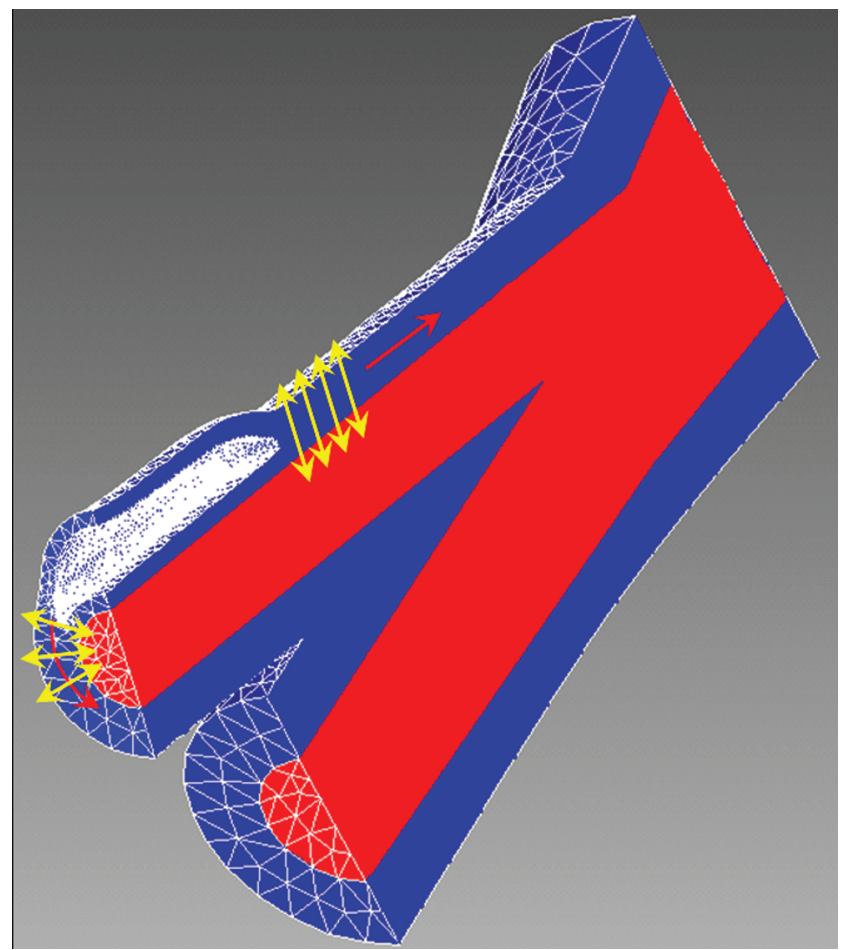

FIG. 6. The FEA model shows further influx of synovial fluid within the nerve. The yellow arrows indicate the direction of the forces causing the tissue to tear. The red arrows indicate the directions in which the cyst will tend to grow.

based on the aforementioned factors. With cyst expansion, cross-over can occur (that is, filling a common epineurial sheath whereby the cyst expands circumferentially around the entire nerve): a cyst originating in a single neural pathway can then affect or involve a second pathway. Pressure fluxes can dictate relative ascent or descent within the primary or secondary pathways. These processes explain the formation of several interconnected intraneural cysts - all dependent on the path of least resistance. In the case of a peroneal intraneural ganglion, different patterns may be seen: 1) continued ascent within the peroneal division of the sciatic nerve; or 2) cross-over within the sciatic nerve allowing cyst dissection within peroneal, tibial, and sciatic nerves.

Admittedly, the observations described of intraneural ganglion cysts are static representations of a dynamic process. ${ }^{42}$ Factors such as intraarticular pressure and/or pressure gradients may lead to dynamic fluxes over time. ${ }^{42}$ The dynamic component of pressure loading and associated dampening of pressure waves in fluid medium could explain differences in cyst propagation near and distant to the joint. These dynamic processes could explain the fluctuating clinical symptoms and signs, 2,12,33,44 as well as the broad spectrum of operative and imaging findings encountered..$^{42}$

\section{Finite Element Analysis Model}

The aforementioned mechanistic explanation for the formation and propagation of intraneural ganglion cysts can be described and studied by FEA, a computational tool that relates forces and deformations based on material properties. This technique has been widely used by engineers to study common clinical problems, and it has been applied to the study of peripheral vascular ${ }^{3,16,17,28,29,35,52,53}$ and cerebrovascular aneurysms..$^{5,9,21,25,30,37,38}$ Because of some similarities in the development of aneurysms and intraneural ganglia, it seems logical that a similar approach can be used to model intraneural ganglia. In FEA, elements-or little volumes of material with ascribed properties-are arranged (Fig. 4) and subjected to prescribed forces and/or displacements. To analyze a given situation, the following components are necessary: material properties (stiffness and strength), geometry (dimensions), and boundary conditions (loads and deformation).

For example, for intraneural ganglia, prediction of cyst propagation patterns requires knowledge of nerve architecture and configuration; the material properties (such as material stiffness and/or material strength) of nerve components; and quantified intrinsic and extrinsic factors (for example, pressure of cyst fluid and surrounding tissues, respectively). It is important to note that a material's stiffness refers to the relative ease in stretching the material for a given applied force; a higher stiffness requiring a larger force for a fixed deformation. A material's strength refers to the greatest force that the material can withstand without undergoing failure.

\section{Nerve Architecture and Configuration}

To show feasibility, a simplified FEA model was constructed to represent a typical neural junction (for example, the intersection of the articular branch and the deep peroneal nerve) using the commercial code ANSYS (Fig. 5). The model consisted of about 60,000 tetrahedralshaped elements. As is shown in Figs. 5 and 6, this simplified nerve was modeled as having a monofascicular region within a surrounding epineurium. The dimensions and the angulation of the nerves that were assigned to the FEA model were determined from values obtained in 2 limbs of 1 cadaveric specimen using a digital caliper with a 0.01-mm accuracy (Industrial Direct Co., Inc.): the mean diameters of the articular branch and the deep peroneal nerve were 1.94 and $2.89 \mathrm{~mm}$, respectively; the deep peroneal nerve portion proximal to the junction with the articular branch and distal to its junction with the superficial peroneal nerve to form the common peroneal nerve was $3.97 \mathrm{~mm}$; the mean angle at which the articular branch meets with the deep peroneal nerve was $16.5^{\circ}$.

\section{Nerve Material Properties}

Assignment of material properties to neural tissue was difficult due to the lack of experimental data available on the mechanical properties of nerve tissue components. Close examination of the nerve fascicular structure ${ }^{51}$ reveals the presence of aligned collagen proteins in a manner similar to ligaments. It was assumed, therefore, that the fascicular element would have stiffness properties (the relative ease in stretching the material for a given applied force) comparable to ligamentous tissue..$^{22}$ The epineurium, in general, has comparatively less col- 


\section{S. Elangovan et al.}

lagen than the peri- and endoneurium; ${ }^{51}$ this region was assumed to have a stiffness of an order of magnitude less than the fascicular region. For computational simplicity, the strength properties (the greatest force that the material can withstand without undergoing failure) were not modeled.

\section{Intrinsic and Extrinsic Factors}

The effect of the pressure and tissue deformation caused by cyst fluid was simulated in the FEA model through the application of force vectors applied onto the inner walls of the cyst (Fig. 5). Because there are no experimental estimates of cyst fluid pressures available from the literature, an approximate value of about $0.5 \mathrm{psi}$ was surmised based on the expected mechanical response of the nerve.

\section{Results}

The results of the FEA modeling indicate the direction in which the cyst will tend to grow (Fig. 6). Examination of the internal forces predicted by the FEA analysis reveals that tensile forces (yellow arrows in Fig. 6) will cause the cyst tissue to tear in a manner that will cause the cyst cavity volume to both increase in directions along the nerve and also radially around the fascicle (red arrows in Fig. 6). It is expected that this process will continue as long as cyst fluid accumulates. Eventually, the cyst will extend, reaching a nerve junction where it will continue to propagate in one or more new directions; the course the cyst takes will be dependent on the architecture of the neural junction and any intrinsic/extrinsic loads at that location.

Future directions of this research will consist of the incorporation of experimental material property data into the FEA simulations and the inclusion of a more intricate representation of the nerve microarchitecture as determined from anatomical and operative dissections. Cyst growth will be simulated as it approaches specific nerve junctions to elucidate the propagation patterns of cysts. The influence of surrounding muscle and bone tissue on the growth behavior of cysts will also be simulated.

\section{Conclusions}

The 3 fundamental principles of the unifying theory are: 1) an articular branch connection from a degenerative joint; 2) cyst fluid dissection along an intraepineurial path of least resistance; and 3) pressure fluxes. ${ }^{42,45,46}$ These principles proposed by clinical and imaging features can be analyzed more scientifically. In this paper, we have provided a mechanistic explanation for the formation and propagation of intraneural ganglia. In addition, this can be simulated and tested using FEA. Further development and manipulation of this model will lead to improved understanding of the clinical problem and, as such, improved clinical outcomes.

\section{References}

1. Adolfsson L: Ganglion cyst communicating with the elbow joint presenting as a distal forearm tumour. J Hand Surg [Br] 22:552-554, 1997

2. Aulisa L, Tamburrelli F, Padua R, et al: Intraneural cyst of the peroneal nerve. Childs Nerv Syst 14:222-225, 1998

3. Berguer R, Bull JL, Khanafer K: Refinements in mathematical models to predict aneurysm growth and rupture. Ann N Y Acad Sci 1085:110-116, 2006

4. Brooks DM: Nerve compression by simple ganglia. A review of thirteen collected cases. J Bone Joint Surg Br 34:391400, 1952

5. Canham PB, Ferguson GG: A mathematical model for the mechanics of saccular aneurysms. Neurosurgery 17:291-295, 1985

6. Carp L, Stout AP: A study of ganglion with special reference to treatment. Surg Gynecol Obstet 47:460-468, 1928

7. Chick G, Alnot JY, Silbermann-Hoffman O: Intraneural mucoid pseudocysts. A report of ten cases. J Bone Joint Surg Br 83:1020-1022, 2001

8. Clark K: Ganglion of the lateral popliteal nerve. J Bone Joint Surg Br 43:778-783, 1961

9. David G, Humphrey JD: Further evidence for the dynamic stability of intracranial saccular aneurysms. J Biomech 36:1143-1150, 2003

10. De Schrijver F, Simon JP, De Smet L, et al: Ganglia of the superior tibiofibular joint: Report of three cases and review of the literature. Acta Orthop Belg 64:233-241, 1998

11. Desy NM, Amrami KK, Spinner RJ: Ganglion cysts and nerves. Neurosurg Q 16:187-194, 2006

12. Drábek P, Filip M, Supšáková $P$, et al: [Relapsing intraneural ganglion of the n. peroneus comm.] Ceska a Slovenska Neurologie a Neurochirurgie 64:300-303, 2001 (Czech)

13. Ellis VH: Two cases of ganglia in the sheath of the peroneal nerve. Br J Surg 24:141-142, 1936

14. Faivre J, Chatel M, Le Beguec P, et al: Les pseudo-kystes mucoides de la gaine du nerf sciatique poplite externe. A propos de deux observations. Rev Neurol 131:709-720, 1975

15. Ferguson LK: Ganglion of the peroneal nerve. Ann Surg 106:313-316, 1937

16. Fillinger MF: The long-term relationship of wall stress to the natural history of abdominal aortic aneurysms (finite element analysis and other methods). Ann N Y Acad Sci 1085:22-28, 2006

17. Fillinger MF, Raghavan ML, Marra SP, et al: In vivo analysis of mechanical wall stress and abdominal aortic aneurysm rupture risk. J Vasc Surg 36:589-597, 2002

18. Godin V, Huaux JP, Knoops PH: Une cause rare de paralysie des muscle releveurs du pied:Le kyste synovial intraneural du nerf sciatique poplite externe. Louv Med 104:281-286, 1985

19. Groulier P, Benaim JL, Curvale G, et al: [Compression of the posterior tibial nerve by a synovial cyst arising from the superior tibio-fibular joint. Report of a case.] Rev Chir Orthop Reparatrice Appar Mot 73:67-69, 1987 (Fr)

20. Gurdjian ES, Larsen RD, Lindner DW: Intraneural cyst of the peroneal and ulnar nerves. Report of two cases. J Neurosurg 23:76-78, 1965

21. Hademenos GJ, Massoud T, Valentino DJ, et al: A nonlinear mathematical model for the development and rupture of intracranial saccular aneurysms. Neurol Res 16:376-384, 1994

22. Hirokawa S, Tsuruno R: Hyper-elastic model analysis of anterior cruciate ligament. Med Eng Phys 19:637-651, 1997

23. Huaux JP, Malghem J, Maldague B, et al: [Pathology of the upper tibiofibular joint-History of cystis - 4 cases reports.] Rev Rhum Mal Osteoartic 53:723-726, 1986 (Fr)

24. Jenkins SA: Solitary tumours of peripheral nerve trunks. J Bone Joint Surg Br 34:401-411, 1952

25. Kyriacou SK, Schwab C, Humphrey JD: Finite element analysis of nonlinear orthotropic hyperelastic membranes. Comput Mech 18:269-278, 1996

26. Lagarrigue J, Robert R, Resche F, et al: [Intraneural syn- 
ovial cysts of the common peroneal nerve.] Neurochirurgie 28:131-134, 1982

27. Lavarde G: Les pseudo-kystes mucoides des nerfs périphériques. J Chir (Paris) 1:97-104, 1968

28. Lu J, Zhou X, Raghavan ML: Computational method of inverse elastostatics for anisotropic hyperelastic solids. Int J Numer Methods Eng 69:1239-1261, 2007

29. Lu J, Zhou X, Rahgavan ML: Inverse elastostatic stress analysis in pre-deformed biological structures: demonstration using abdominal aortic aneurysms. J Biomech 40:693-696, 2007

30. Ma B, Lu J, Harbaugh RE, et al: Nonlinear anisotropic stress analysis of anatomically realistic cerebral aneurysms. J Biomech Eng 129:88-96, 2007

31. Malghem J, Vande BB, Lecouvet F, et al: Les kystes mucoides atypiques. JBR-BTR 85:34-42, 2002

32. Malghem J, Vande berg BC, Lebon C, et al: Ganglion cysts of the knee: articular communication revealed by delayed radiography and CT after arthrography. AJR Am J Roentgenol 170:1579-1583, 1998

33. Petit-Lacour MC, Pico F, Rappoport N, et al: Fluctuating peroneal nerve palsy caused by an intraneural cyst. J Neurol 249:490-491, 2002

34. Poppi M, Nasi MT, Giuliani G, et al: Intraneural ganglion of the peroneal nerve: an unusual presentation. Case report. Surg Neurol 31:405-406, 1989

35. Raghavan ML, Vorp DA, Federle MP, et al: Wall stress distribution on three-dimensionally reconstructed models of human abdominal aortic aneurysm. J Vasc Surg 31:760-769, 2000

36. Robert R, Resche F, Lajat Y, et al: Kyste synovial intraneural du sciatique poplite externe. Apropos d'un cas. Neurochirurgie 26:135-143, 1980

37. Shah AD, Humphrey JD: Finite strain elastodynamics of intracranial saccular aneurysms. J Biomech 32:593-599, 1999

38. Simkins TE, Stehbens WE: Vibrations recorded from adventitial surface of experimental aneurysms and arteriovenous fistulas. Vasc Surg 8:153-165, 1974

39. Spinner RJ, Amrami KK, Angius D, et al: Peroneal and tibial intraneural ganglia: correlation between intraepineurial compartments observed on magnetic resonance images and the potential importance of these compartments. Neurosurg Focus 22(6):E17, 2007

40. Spinner RJ, Amrami KK, Kliot M, et al: Suprascapular intraneural ganglia and glenohumeral joint conections. J Neurosurg 104:551-557, 2006

41. Spinner RJ, Amrami KK, Rock MG: The use of MR arthrography to document an occult joint communication in a recurrent peroneal intraneural ganglion. Skeletal Radiol 35:172-179, 2006

42. Spinner RJ, Amrami KK, Wolanskyj AP, et al: Dynamic phas- es of peroneal and tibial intraneural ganglia formation: a new dimension added to the unifying articular theory. J Neurosurg 107:296-307, 2007

43. Spinner RJ, Atkinson JL, Harper CM Jr, et al: Recurrent intraneural ganglion cyst of the tibial nerve. Case report. J Neurosurg 92:334-337, 2000

44. Spinner RJ, Atkinson JL, Scheithauer BW, et al: Peroneal intraneural ganglia: the importance of the articular branch. Clinical series. J Neurosurg 99:319-329, 2003

45. Spinner RJ, Atkinson JL, Tiel RL: Peroneal intraneural ganglia: the importance of the articular branch. A unifying theory. J Neurosurg 99:330-343, 2003

46. Spinner RJ, Carmichael SW, Wang H, et al: Patterns of intraneural ganglion cyst descent. Clin Anat 21:233-245, 2008

47. Spinner RJ, Desy NM, Amrami KK: Cystic transverse limb of the articular branch: a pathognomonic sign for peroneal intraneural ganglia at the superior tibiofibular joint. Neurosurgery 59:157-166, 2006

48. Spinner RJ, Desy NM, Rock MG, et al: Peroneal intraneural ganglia. Part I. Techniques for successful diagnosis and treatment. Neurosurg Focus 22(6):E16, 2007

49. Spinner RJ, Mokhtarzadeh A, Schiefer TK, et al: The clinico-anatomic explanation for tibial intraneural ganglion cysts arising from the superior tibiofibular joint. Skeletal Radiol 36:281-292, 2007

50. Spinner RJ, Scheithauer BW, Desy NM, et al: Coexisting secondary intraneural and vascular adventitial ganglion cysts of joint origin: a causal rather than a coincidental relationship supporting an articular theory. Skeletal Radiol 35:734-744, 2006

51. Topp KS, Boyd BS: Structure and biomechanics of peripheral nerves: nerve responses to physical stresses and implications for physical therapist practice. Phys Ther 86:92-109, 2006

52. Truijers M, Pol JA, Schultzekool LJ, et al: Wall stress analysis in small asymptomatic, symptomatic and ruptured abdominal aortic aneurysms. Eur J Vasc Endovasc Surg 33:401-407, 2007

53. Venkatasubramaniam AK, Fagan MJ, Mehta T, et al: A comparative study of aortic wall stress using finite element analysis for ruptured and non-ruptured abdominal aortic aneurysms. Eur J Vasc Endovasc Surg 28:168-176, 2004

54. Wainwright AM, Burge PD: Synovial cyst of the pulp of the little finger-origin from the wrist joint. J Hand Surg [Br] 27:503-506, 2002

Manuscript submitted October 10, 2008.

Accepted November 19, 2008.

Address correspondence to: Robert J. Spinner, M.D., Department of Neurosurgery, Mayo Clinic, Rochester, Minnesota 55905. email: spinner.robert@mayo.edu. 